\title{
Assessment of Nanofibers Filtration for Textile Waste-water Treatment EI Messiry $\mathbf{M}^{*}$, Aloufy $\mathbf{A}$ and Elmor $\mathbf{M}$ \\ Textile Department, Faculty of Engineering, Alexandria University, Egypt
}

\begin{abstract}
The finished fabrics need to be bleached, dyed, and printed and these processes require at least 100 liters of water for each ton of fabric. The recycle of industrial wastewater is one of the solutions for efficient use of water resources.

In this work, designed filter unit was suggested to be used for the filtration of the wastewater from textile dyeing and finishing mill. Three designs were manufactured using yarns and yarns covered with nanofibers layers were introduced. The results of testing different designs indicate the improvement in the filtration efficiency. Moreover, a case study in the dyeing and finishing textile mill designated that the treatment of the wastewater by the designed filters advanced the filtration efficiency.

Unit performance of wastewater treatment was: COD decreased to $52 \mathrm{mg} / \mathrm{L}$, TSS decreased to $300 \mathrm{mg} / \mathrm{L}$, and Turbidity to 70 NTU. The designed filtration unit is suitable to be used, in particular in textile dyeing and finishing SME with small discharge, and can produce treated effluent satisfying the standards regulating wastewater.
\end{abstract}

Keywords: Nano fibers; Water filters; Multi-layer filters; Multi-stage filters; Nano-filtration; SME

\section{Introduction}

The textile industry has a major impact on Egypt's economy. It accounts for more than $34 \%$ of the total export [1]. The export portfolio of Egypt indicates that textile export comes after the agriculture products. It represents $27 \%$ of total manufactured production in Egypt, ranking the second. The dyeing and finishing mills, more than 4000, are distributed all over Egypt, most of them are SME. The textile dyeing industry consumes large quantities of water and produces immense volumes of wastewater from the different steps in the dyeing and finishing processes. In average water consumption in textile dyeing and finishing process are: for cotton industry $50-200 \mathrm{~L} / \mathrm{kg}$, for wool industry $75-200 \mathrm{~L} / \mathrm{kg}$, and for synthetic fibers industry 10-100 L/kg [2].

The specific water use for fabric varies from 60 to $400 \mathrm{~L} / \mathrm{kg}$, depending on the type of fabric wet application. This entire amount should be treated before discharge into the sewage system. In the recent decade, wastewater that is discharged by dye manufacturing and textile finishing industries has become an environmental concern. The legal requirements concerning discharge of contaminated wastewater are reinforced in many countries. Gohary et al. [3] proposed the following: replacement of acetic acid by formic acid, elimination of the bisulfite treatment step after full bleaching of cones or fabric, replacing chemical scouring by bio scouring, avoiding the use of carrier in polyester dyeing and replacing mono-functional reactive dyes by bi-functional dyestuffs. The use of up flow Anaerobic Sludge Blanket reactor, followed by either activated sludge treatment or chemical coagulation treatment, can produce treated effluent satisfying the standards.

Hamdy Seif and Moheb Malak [4] developed a filtration system for a textile wastewater consisting of aerobic treatment in combination with the use of filtration with a result in a significant TSS, COD, and color removal. It appears that an ideal treatment process for satisfactory recycling and reuse of textile effluent water should involve the following refractory organic compounds and dyes may be electrochemically oxidized to biodegradable constituents before the wastewater is subjected to biological treatment under aerobic conditions [5]. The complete textile manufacturing process engages a number of individual unit operations, each generating effluents of substantially different qualities. Textile processing effluent characteristics are classified into 7 categories [6].
The nature of textile wastewater, in terms of broad parameters such as BOD, COD, and TSS, has extensively been reviewed by different authors [7-15]. The average concentration and specific loads TSS for main operations in textile finishing are: desizing 16000-32000, scouring or kiering 7600-17000, bleaching 2300-14000, mercerizing 600-1900, dyeing 500-14000.

Microfliteration, ultrafilteration, nanofilteration, reverse osmosis are recommended, depending on the particle size of pollutant. Amparo [16] stated that ultrafiltration, nanofiltration, and reverse osmosis have been applied. Biological treatment processes, chemical processes, adsorption, membrane treatment, ultrafiltration membranes are used for chemicals recovery while reverse osmosis (RO) and nanofiltration (NF) are normally the only possible alternatives when the salts must be removed to produce high quality water for reuse [6].

Amparo Bes-Piá et al. [16] study the behavior of different NF membranes for the reclamation of a secondary textile effluent in rinsing processes; six NF membranes were tested at different volume concentration factors in order to select the most appropriate one.

M. Marcucci et al. [17] implicates that in the case of the use of NF as the final membrane process, the values were found of COD 142 $\mathrm{mg} / \mathrm{L}$ and TSS $12 \mathrm{mg} / \mathrm{L}$, while in the case of the use of RO as the final membrane process COD $147 \mathrm{mg} / \mathrm{L}$ and TSS $49 \mathrm{mg} / \mathrm{L}$, and Turbidity 6.8 NTU. NF does not reach the retention behavior of RO. This is due to the fact that an ultrafiltration filter has a pore size around 0.01 microns but microfiltration filter has a pore size around 0.1 micron, a nanofiltration filter has a pore size around 0.001 micron, and a reverse osmosis filters have a pore size around 0.0001 micron.

*Corresponding author: El Messiry M, Textile Department, Faculty of Engineering Alexandria University, Egypt, Tel: +20 3 5921675; E-mail: mmessiry@yahoo.com

Received March 23, 2016; Accepted April 29, 2016; Published May 03, 2016

Citation: El Messiry M, Aloufy A, Elmor M (2016) Assessment of Nanofibers Filtration for Textile Waste-water Treatment. J Appl Mech Eng 5: 211. doi:10.4172/21689873.1000211

Copyright: ( 2016 El Messiry M, et al. This is an open-access article distributed under the terms of the Creative Commons Attribution License, which permits unrestricted use, distribution, and reproduction in any medium, provided the original author and source are credited. 
Citation: El Messiry M, Aloufy A, Elmor M (2016) Assessment of Nanofibers Filtration for Textile Waste-water Treatment. J Appl Mech Eng 5: 211. doi:10.4172/2168-9873.1000211

Nanotechnology for water and wastewater treatment is gaining momentum globally [18]. The unique properties of nanomaterial and their convergence with current treatment technologies present great opportunities to revolutionize water and wastewater treatment. For small and medium dye house the flow rate of wastewater is low and the need for efficient wastewater treatment unit became necessary. This is the main objective of this work.

\section{Experimental Work}

\section{Design of filter unit}

The main objective of this work is to design multilayer wastewater filters using:

- Design I; Different yarns of different materials cross wound on the surface of perforated cylinder.

- $\quad$ Design II; Hybrid multilayer filters made of yarns and layers of nanofibers. The number of nanofibers layers depends on the porosity required.

- Deign III; Combination of two above.

The construction features of the filter unit are as follows:

1- The inner tube with a length of $7 \mathrm{~cm}$ and diameter $2.5 \mathrm{~cm}$.

2- 30 holes of diameter $10 \mathrm{~mm}$ have been drilled on the perimeter of pipe in 6 rows along the tube length. Hence, the total number of holes is 180 .

Figure 1 shows filter unit inner cylinder.

\section{Design of water filtration setup}

In order to test the designed filters, a setup was assembled. The setup consists of water storage tank (500 L), water pump (350 watt), and the filtration unit fixed in the way that water will pump into at a predetermined constant pressure (Figure 2). Figure 3 shows a schematic diagram of filtration experimental setup.

\section{Method for measuring the filter porosity}

The filtration depends generally on the filter porosity. Figure 4 shows sketch of filter permeability setup. All filter designs should have the same total porosity. For that purpose, thickness of the filtration

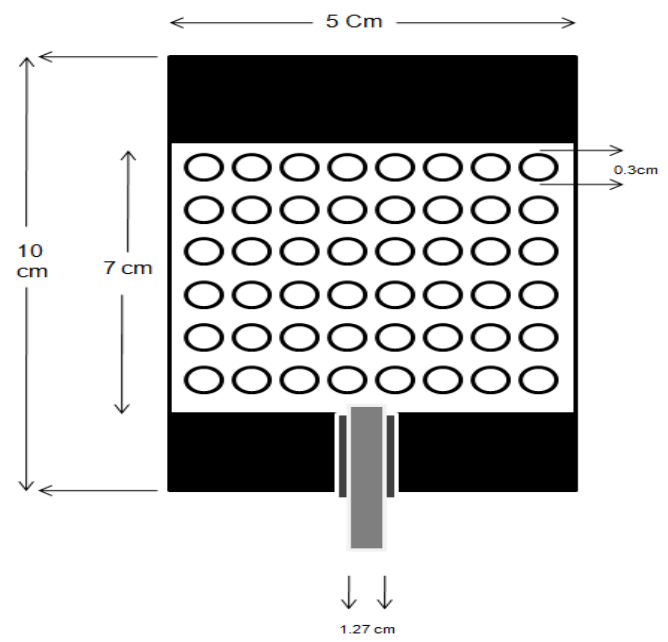

Figure 1: Inner cylinder of the filter.

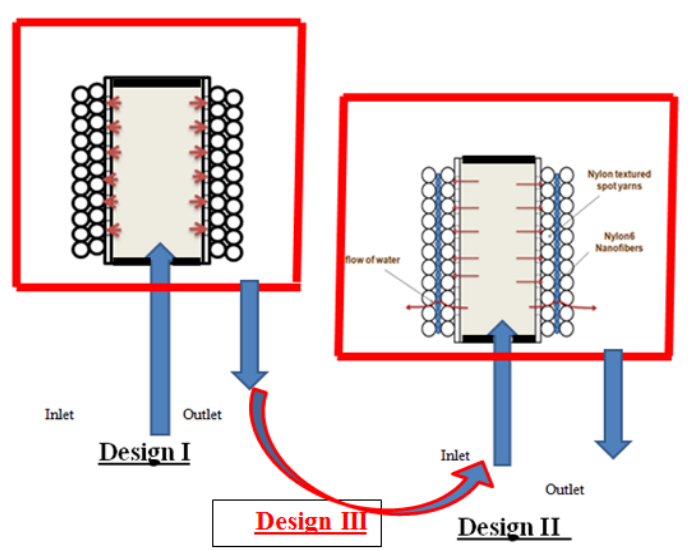

Figure 2: Sketch of filtration units design.

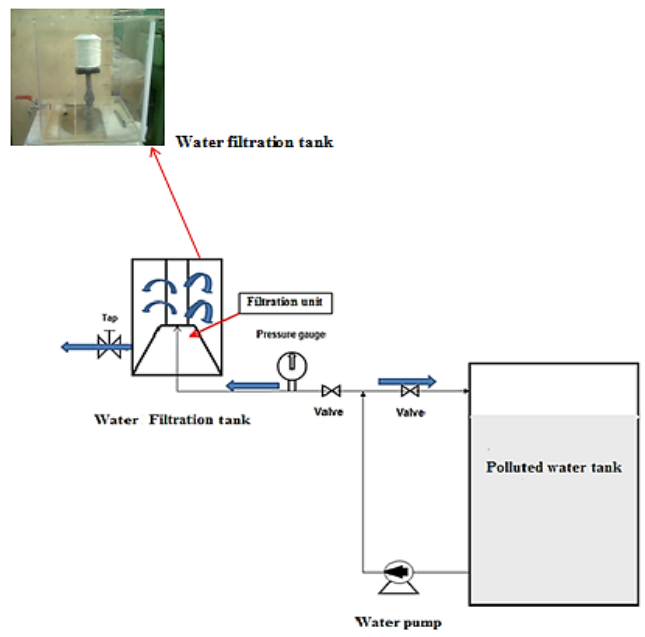

Figure 3: Schematic diagram of filtration experimental setup.

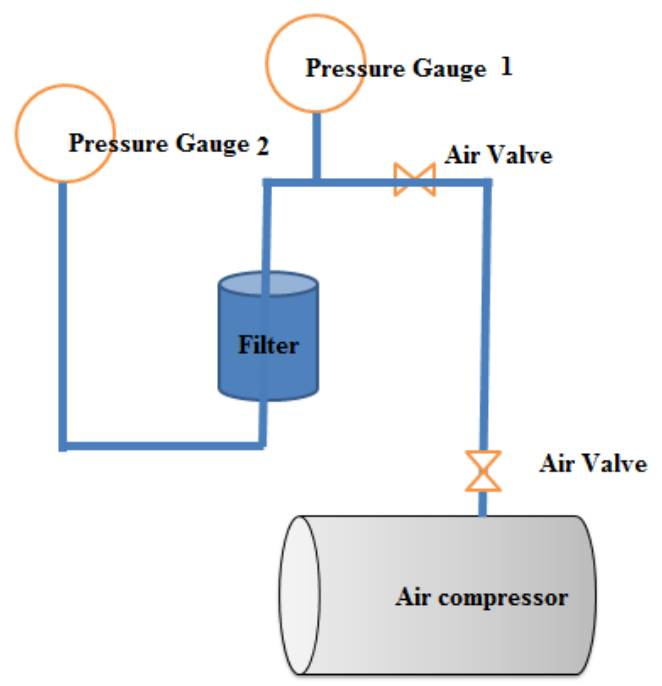

Figure 4: Sketch of filter permeability setup. 
Citation: El Messiry M, Aloufy A, Elmor M (2016) Assessment of Nanofibers Filtration for Textile Waste-water Treatment. J Appl Mech Eng 5: 211. doi:10.4172/2168-9873.1000211

Page 3 of 8

media was changed and in each case the pressure drop inside the filter was measured. The minimum weight of yarns was determined to satisfy the required conditions for the pressure drop to be equal to $10 \mathrm{kPa}$.

\section{Filtration media designs}

\section{Design I}

In order to manufacture the filter media, a winding head was used to build a layer of yarns on the filter unit inner cylinder forming a cheese package. The steps for the preparation of the filter are:

1. Yarns were wound on the inner cylinder of the filter on a cross winding head.

2. The thickness of the yarn layers has been determined by measuring the drop pressure across the filter wall.

3. After winding, the inner cylinder of the filter was sealed from both sides; several layers of sealing material (silicon) have been used to insure that the flow of water passes through the yarn's layer only.

Several types of yarns were used of specifications given in Table 1.

\section{Design II, Hybrid filters}

Filter media is formed from Nylon spot textured yarn, wound on the internal cylinder of the filter on a cross winding head, nanofibers layers were electro spun directly on the layers of the filter, as shown in Figure 2, followed by the several layers of nylon yarns wound, and by the deposition of nanofibers layer on the electro spinning unit, in the case if two layers of nanofibers are required. The filter's cylinder was rotated in order to distribute the nanofibers on the circumference surface of the filter. This process is repeated to design the required filter media construction.

The percentage of the nanofibers is $0.6-0.7 \%$ of the filter weight. In this work, filters with one, two, and three layers of nanofibers were constructed. Table 2 gives the specifications of the designed filters. Nylon6 solution with different concentrations, $15 \%, 18 \%, 20 \%, 24 \%$, $26 \%$, and $28 \%$ by weight, were prepared by dissolving Nylon pellets in formic acid (98-100\%). The solutions were prepared at a constant temperature of $70^{\circ} \mathrm{C}$. The spinneret (pipette) of diameters $0.9 \mathrm{~mm}$ and

\begin{tabular}{|c|c|c|}
\hline Filter code & Material & Yarn Count tex \\
\hline $\mathbf{1}$ & Cotton & 51 \\
\hline $\mathbf{2}$ & Cotton & 38 \\
\hline $\mathbf{3}$ & Cotton & 14 \\
\hline $\mathbf{4}$ & Polyester & 85 \\
\hline $\mathbf{5}$ & Polyester & 54 \\
\hline $\mathbf{6}$ & Nylon spot textured & Denier 1800/144 \\
\hline
\end{tabular}

Table 1: Specifications of the yarns.

\begin{tabular}{|l|l|c|c|c|}
\hline Filter & Material & $\begin{array}{c}\text { Weight } \\
\text { filtration } \\
\text { media (gm.) }\end{array}$ & Yarn specifications & $\begin{array}{c}\text { No. of } \\
\text { Nanofiber } \\
\text { layers }\end{array}$ \\
\hline 1 & $\begin{array}{l}\text { Nylon spot } \\
\text { textured and } \\
\text { NFs }\end{array}$ & 241.07 & $\begin{array}{c}\text { Nylon spot textured(Denier } \\
1800 / 144) \text { and Nanofiber } \\
\text { (d=388.8nm) }\end{array}$ & 1 layer \\
\hline 2 & $\begin{array}{l}\text { Nylon spot } \\
\text { textured and } \\
\text { Nanofiber }\end{array}$ & 238.26 & $\begin{array}{c}\text { Nylon spot textured(Denier } \\
1800 / 144) \text { and Nanofiber diameter } \\
\text { of first layer }(\mathrm{d}=388.8) \text { the } \\
\text { second layer 190 nm) }\end{array}$ & 2 layers \\
\hline 3 & $\begin{array}{l}\text { Nylon spot } \\
\text { textured and } \\
\text { Nanofiber }\end{array}$ & 242.58 & $\begin{array}{c}\text { Nylon spot textured(Denier } \\
1800 / 144) \text { and Nanofiber diameter } \\
\text { of first layer }(\mathrm{d}=388.8 \mathrm{~nm}) \text { the } \\
\text { second layer }(\mathrm{d}=190 \mathrm{~nm}) \text {,third } \\
\text { layer }(\mathrm{d}=71.1 \mathrm{~nm})\end{array}$ & 3 layers \\
\hline
\end{tabular}

Table 2: Specifications of the designed filters.
$1.2 \mathrm{~mm}$ were used to produce nanofibers with various diameters. The optimum distance between the collector and the spinneret was found to be $15 \mathrm{~cm}$ and voltage $25 \mathrm{Kv}$. Figure 5 shows setup of electro spinning for the direct laying of nanofibers on the filter surface. Two inclinations of the path of the nanofibers from the feeder to the collecting surface, $90^{\circ}$ and $45^{\circ}$ were tested.

Table 3 gives the SEM of the nanofibers mats spun at different inclined paths. The alteration in the layout of the fibers may be due to the effect of the gravitational force which in the case of $45^{\circ}$ inclined path has lesser effect, so that the arrangement of the fibers in the mat is different and coefficient of variation of the nanofibers diameter is less in the case of the inclined path.

The diameters of spun nanofibers for filter Design II were: 388.8 $\mathrm{nm}, 190 \mathrm{~nm}$, and $77.1 \mathrm{~nm}$.

\section{Design III, Two stage filter}

To increase filtration efficiency, two stage filters in series was tried. Designed system consists of:

1- First filtration stage: filter using Polyester yarns ( $\mathrm{Ne}=11.16)$.

2- Second filtration stage: using 3 layers nanofibers Nylon6 with different nanofibers diameter, $388.8 \mathrm{~nm}, 190 \mathrm{~nm}$, and $77.1 \mathrm{~nm}$.

\section{Analysis of Wastewater}

The water was collected from wastewater of Textile Company's dyeing and finishing unit. For the determination of each type of filter efficiency, three samples of water before the filtration and three other samples after filtration were tested for the assessing the following properties:

COD (Chemical Oxygen Demand),

TSS (Total Suspended Solids),

TDS (Total Dissolved Solids), and

Turbidity NTU

The characterizations of above parameters are according to water testing standards ASTM [19].

\section{Results and Discussion}

\section{Filter design parameters}

Basically, winding unit rotates the filter inner cylinder about

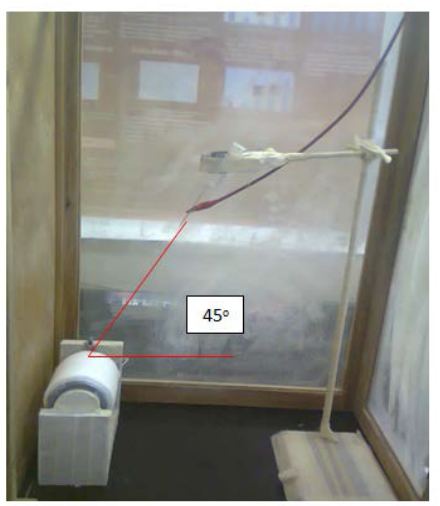

Figure 5: Electro spinning setup. 
Citation: El Messiry M, Aloufy A, Elmor M (2016) Assessment of Nanofibers Filtration for Textile Waste-water Treatment. J Appl Mech Eng 5: 211. doi:10.4172/2168-9873.1000211

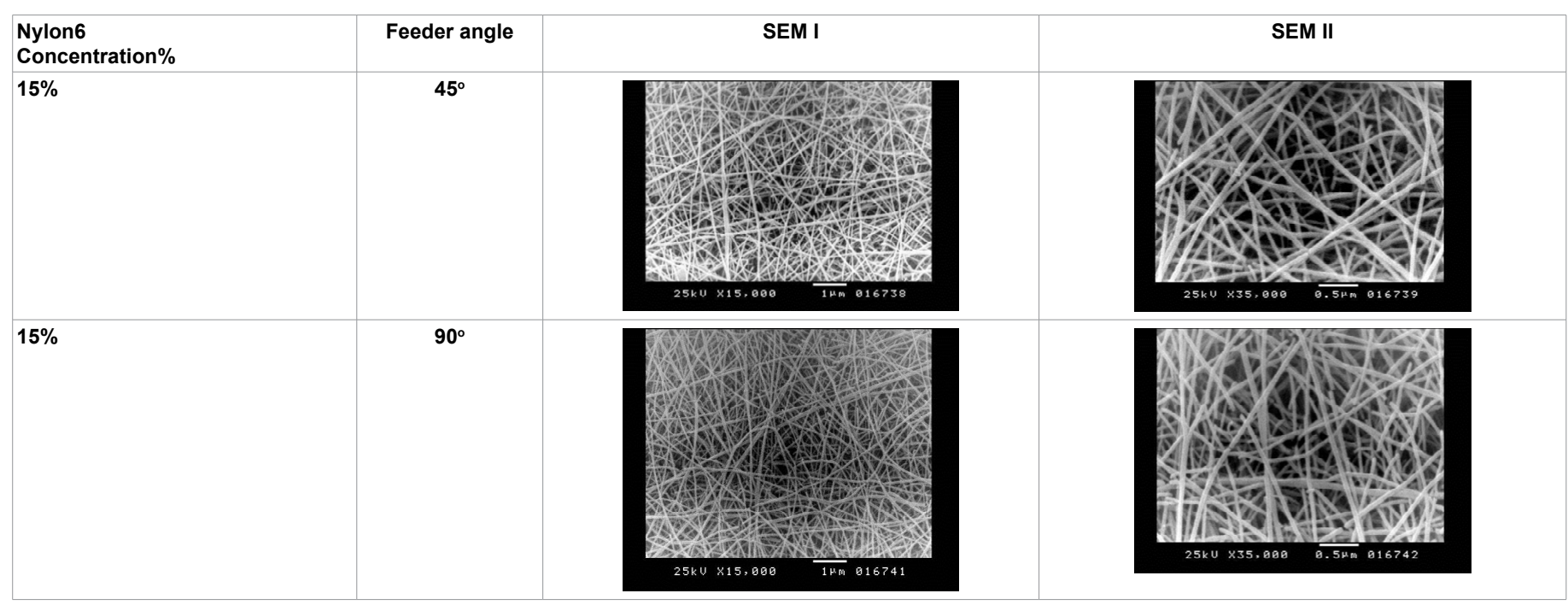

Table 3: SEM of the produced nano fibers mats.

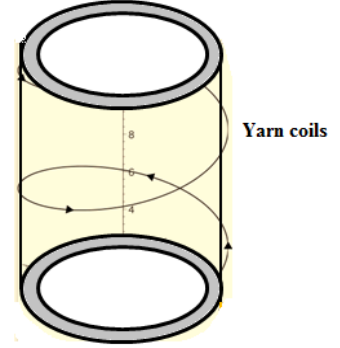

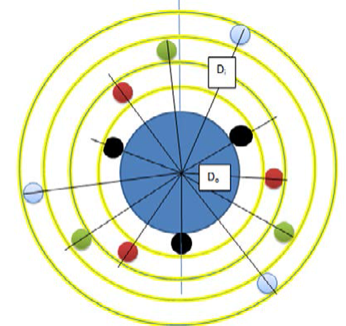

(b) (a) Yarn path on the filter circumference.

(b) The laying of the yarns in the different layers of filter cross section.

Figure 6: Filtration media construction.

horizontal axis, yarn being fed in a direction perpendicular to the package axis. Yarn guide will reciprocate along the axis of the rotated cylinder causing the yarn to form helical coils on the drum surface as shown in Figure 6a. Cross winding yarn in the second layer will follow a helical path in the opposite direction. The laying of the yarns in cross section of the filter will be as shown in Figure $6 \mathrm{~b}$.

The yarn cross section in the successive layers will be shifted by angle $\beta$, after a certain number of layers; the yarn cross section in the last layer will coincide on the first layer, forming complete cover. This number of layers depends on the winding ratio and traverse ratio chosen. Figure 7 shows the theoretical relation of the number of covered layers as a function of the yarn "tex" for a certain filtration media weight.

The curve in Figure 8 indicates that the fine yarns form filtration media with a low porosity and it reduces the pore size due to the overlapping of the yarns in the successive layers, which depends on how many times the yarns will be closing the distance between the yarns helixes, and consequently, influence the filtration efficiency. Our theoretical model was created by considering that one repeating unit cell of the yarns layout in the filtration media structure consists of a covered layer, as shown in Figure 6b.

By determining the volume of the yarns in the filtration media and

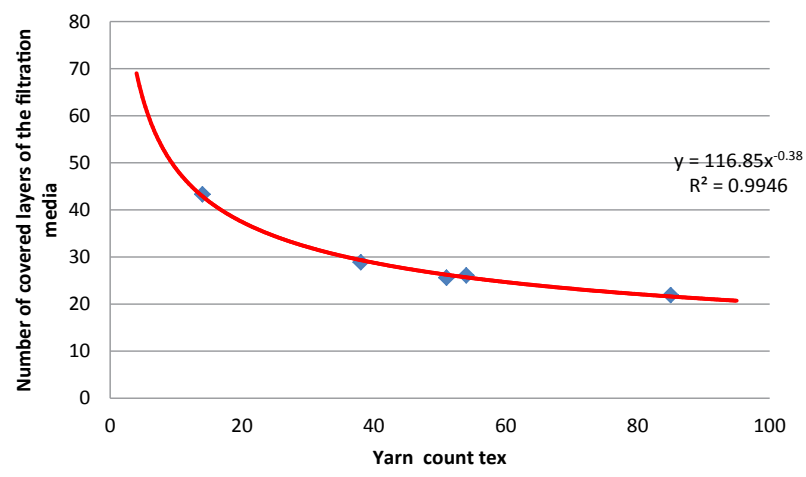

Figure 7: Number of covered layers of the filtration media versus the yarn count.

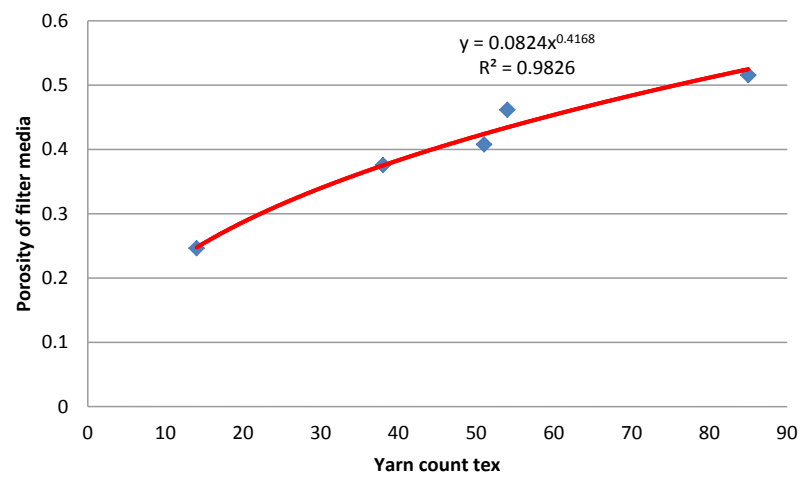

Figure 8: Filter porosity versus the yarn count in tex.

knowing the weight and density of the filtration media, the porosity of the filter can be calculated as follows:

\section{$\varepsilon 1-($ Yarn volume/Total filteration media volume) - (1)}

The increase in the filtration media weight means that a longer length of the yarns is wound on filter body, escalating the probability of the yarns to cover the spaces between the coiled yarns, consequently the final porosity of the filter media will decrease. For the fine yarns, 
the length of the yarn increases to form a filtration media of the same weight and the number of wound layers increases as well. The size of the pores depends on the yarn diameter which is directly proportional to yarn square root of its tex.

Moreover, the porosity of the filtration media is affected by the number of the complete covered layers of the yarn. From the above analysis, the following can be concluded to reduce the filter porosity: decrease the yarn count "tex", increase winding ratio, use yarns with high packing density.

In this work, the design of several filters was manufactured trying to find higher filtration efficiency. To control the porosity of the different designed filters, the setup for measuring the air permeability was used determining the weight of the filtration media that causes a drop in pressure of $10 \mathrm{kPa}$. For each design the weight of the material was changed till a drop of pressure of $10 \mathrm{kPa}$ was reached. Figure 9 shows the relationship between the drop of pressure and filter media weight.

\section{Effect of the filter design on the filtration efficiency}

The efficiency of the designed filters of specifications given in Table 1 was measured for the different parameters of the wastewater. Commonly performed tests for the analysis of the wastewater are: COD, TSS, TDS, and Turbidity. The measured values are determined before and after passing the wastewater through the each of the designed filters. Solids are found in wastewater streams in two forms, suspended and dissolved. Suspended solids will not pass through a filter, whereas dissolved solids will. It's expected that the designed filters can't affect the level of the TDS. Total suspended solids (TSS) include all particles suspended in water which will not pass through a filter. The efficiency of the filter increases with the potential of the filter to prevent the passage of the solid which depends on the filter media porosity and tortuosity. The swelling of the fibers due to the water absorption will also decrease the capillarity in the filtration media.

\section{Design I}

Figure 10 gives a comparison between the different filters of Design I. The analysis of the results for these filters indicates that:

- $\quad$ All the filters do not affect the value of TDS.

- The filter made from the cotton yarns of count 14.3 tex gives the higher efficiency, considering the values of TSS and Turbidity.

- $\quad$ The filter made from the Polyester yarns of count 85 and 54.5 tex gives the higher efficiency, considering the values of COD.

- All filter characteristics of the effluent is less than required by the Egypt standards [20] except TDS.

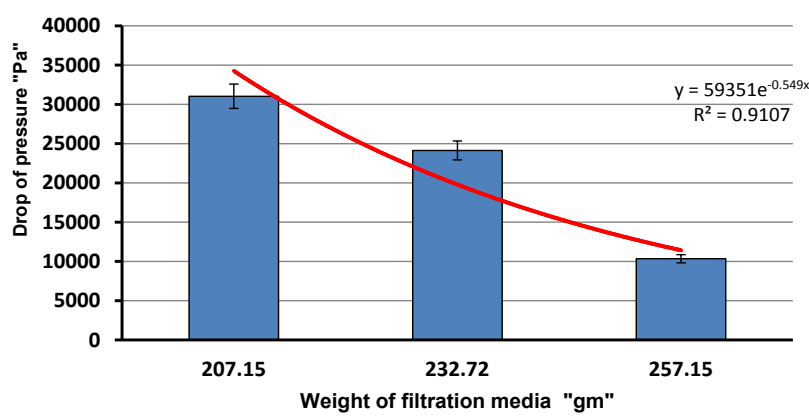

Figure 9: Drop of pressure across the filter versus weights of filtration media.

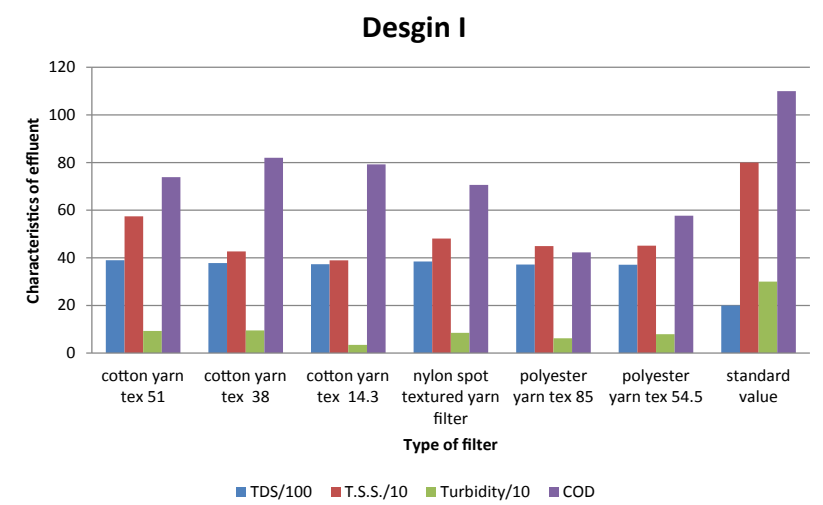

Figure 10: Design I filter characteristics of the effluent regarding COD, TSS, TDS, and turbidity.

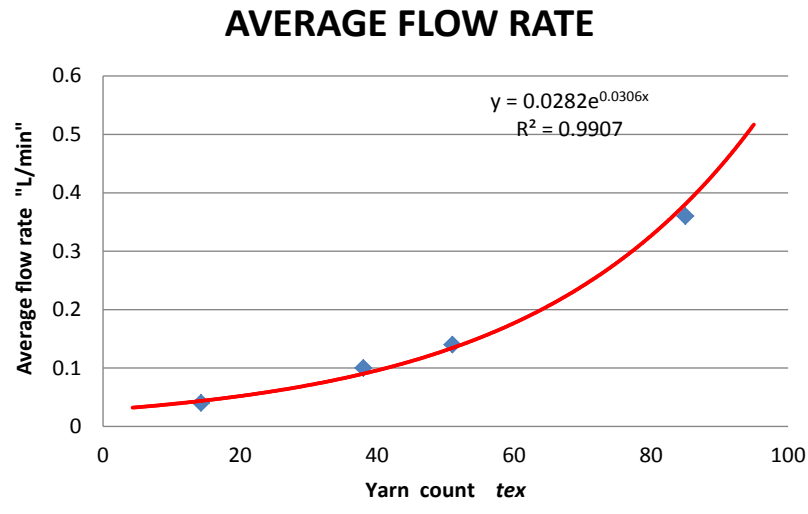

Figure 11: Average flow rate as a function of the yarn count tex.

Figure 10 shows Design I filter characteristics of the effluent regarding COD, TSS, TDS, and Turbidi The flow rate of water through the different filters of Design I depends on the porosity of the filtration media. Figure 11 illustrates the flow rate of water as a function of the yarn count tex, indicating that the finer is the yarn used the lesser will be the water flow rate due to the lower porosity, confirming the theoretical approach given in Figure 8.

\section{Design II}

Nanofibers characterization: The second type of filters was designed using filtration media made from Nylon spot textured yarns adding on it several layers of Nano Nylon fibers. To find the best conditions for processing the Nano nylon fibers by means of electrospinning method, fiber characterization was done by analyzing Nano fiber's Electron Microscope images.

Figure 12 indicates the relationship between the fiber diameter and the percentage of Nylon6 polymer concentration, which confirms that the higher is the Nylon6 concentration percentage, the higher will be the mean diameter of the fiber.

Several filters were manufactured using:

- One layer of Nylon6 (24\%) nanofiber,

- Two layers of Nylon6 (24\% and 20\%) nanofibers, and

- Three layers (24\%, 20\% and 18\%) nanofiber. 
Citation: El Messiry M, Aloufy A, Elmor M (2016) Assessment of Nanofibers Filtration for Textile Waste-water Treatment. J Appl Mech Eng 5: 211. doi:10.4172/2168-9873.1000211

The diameter of the nanofibers in the successive layers in the filtration media decreases to increase the filtration efficiency.

Table 4 gives the SEM of the different nanofiber mats with varied Nylon6 concentration percentage. The fiber diameter $\mathrm{CV} \%$ is varied between $16 \%$ and $28 \%$.

Analysis of the filtration efficiency of Design II filters: Several

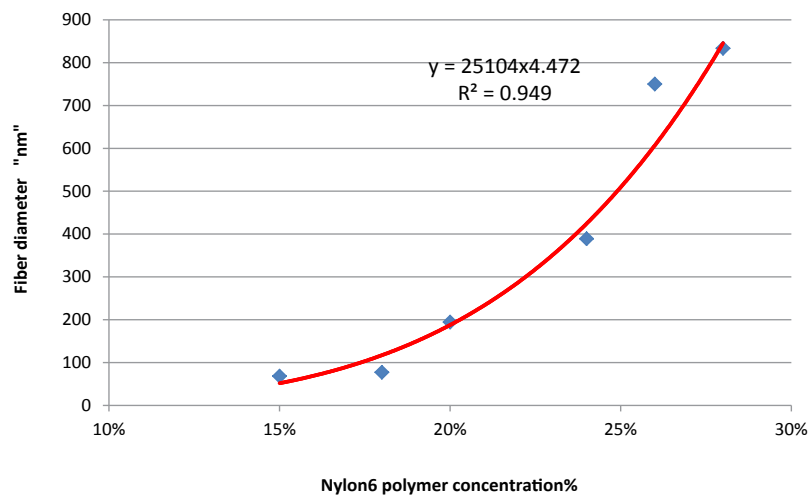

Figure 12: Fiber diameter versus Nylon6 concentration (\%). filters were manufactured using one layer of Nylon 6 (24\%) nanofibers, two layers of Nylon6 (24\% and 20\%) nanofibers, and three layers of Nylon6 (24\%, 20\%, and 18\%) nanofibers.

Table 5 gives the values of the wastewater parameters after filtration by the three filters. Figure 13a shows the comparison of the values of TDS, TSS, Turbidity, and COD for the filtered water, which indicates that three layer filters give the best result.

Figure 13b indicates that with the increasing in the number of nanofibers layers, the efficiency of filter increases. Furthermore, the value of TSS reduces distinctly.

\section{Design III}

From the above analysis of the filters Design I and Design II, it is clear that some of the filters are able to reduce the values of certain wastewater characteristics better than the others. In order to improve the efficiency of filtration, two stage filters was designed, consisting of the Designs I in the series with the Design II (three layer nanofibers filter). Figure 14 gives the assessment of the three designs that shows a significant reduction in Turbidity and TSS.

Figure 15 shows the all filters reduce values of TDS, TSS, Turbidity, and COD. Filters Design II and Design III are more efficient in reducing

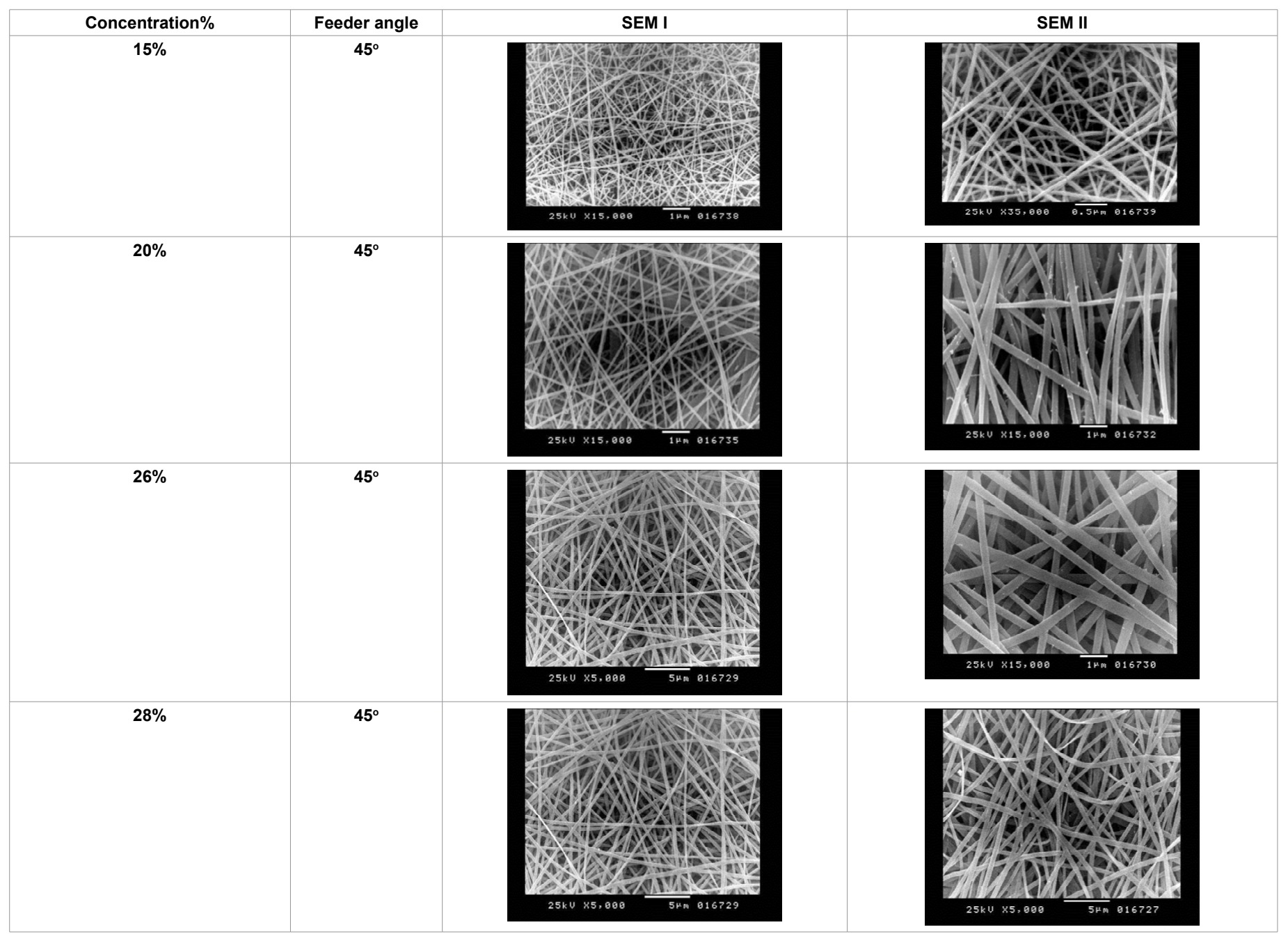

Table 4: SEM for Nylon6 nanofiber mats with different concentration\%. 
Citation: El Messiry M, Aloufy A, Elmor M (2016) Assessment of Nanofibers Filtration for Textile Waste-water Treatment. J Appl Mech Eng 5: 211. doi:10.4172/2168-9873.1000211

\begin{tabular}{|l|c|c|c|c|c|}
\hline & $\begin{array}{c}\text { Nylon spot } \\
\text { textured } \\
\text { yarn }\end{array}$ & $\begin{array}{c}\text { One } \\
\text { layer of } \\
\text { nanofibers }\end{array}$ & $\begin{array}{c}\text { Two } \\
\text { layers of } \\
\text { nanofibers }\end{array}$ & $\begin{array}{c}\text { Three } \\
\text { layers of } \\
\text { nanofibers }\end{array}$ & $\begin{array}{c}\text { Standard } \\
\text { Egy. Law } \\
\text { [20] }\end{array}$ \\
\hline TDS mg/L & 3845 & 3804 & 3740 & 3763 & 2000 \\
\hline TSS mg/L & 481 & 411 & 591 & 299 & 800 \\
\hline Turbidity NTU & 84.8 & 73.8 & 70.1 & 69.5 & 300 \\
\hline COD mg/L & 70.6 & 65 & 53.6 & 51.9 & 110 \\
\hline
\end{tabular}

Table 5: Characteristics of effluent after filtration.

$\mathrm{a}$

\section{EFFECT OF NANOFIBERS LAYERS}

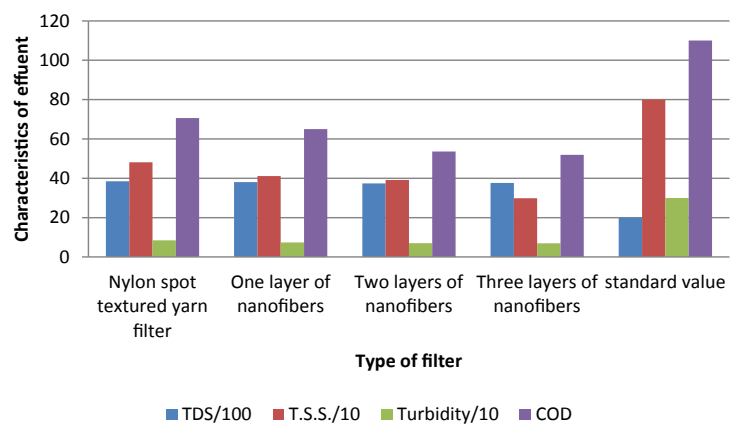

b

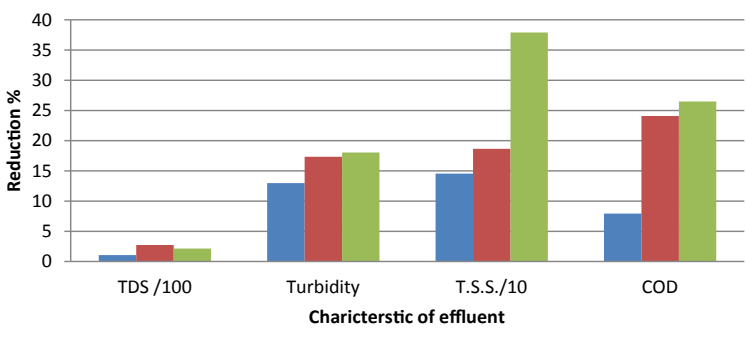

One layer of nanofibers - Two layers of nanofibers $\quad$ Three layers of nanofibers

Figures 13: Performance of Design II filters.

Two stages filtration

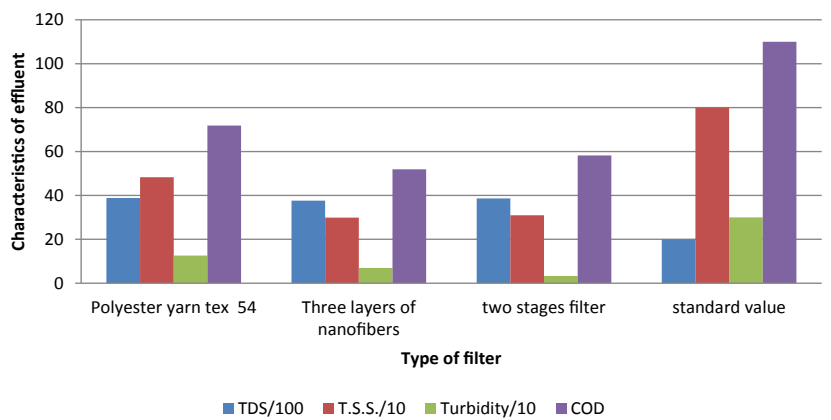

Figure 14: Comparison between the different filters designs.

in Turbidity due to the presence of nanofibers layers which increase the ability of the filter to collect the micro size particles.

\section{Case study}

The results of the water treatment station in a textile company are compared with designed system consisted of:

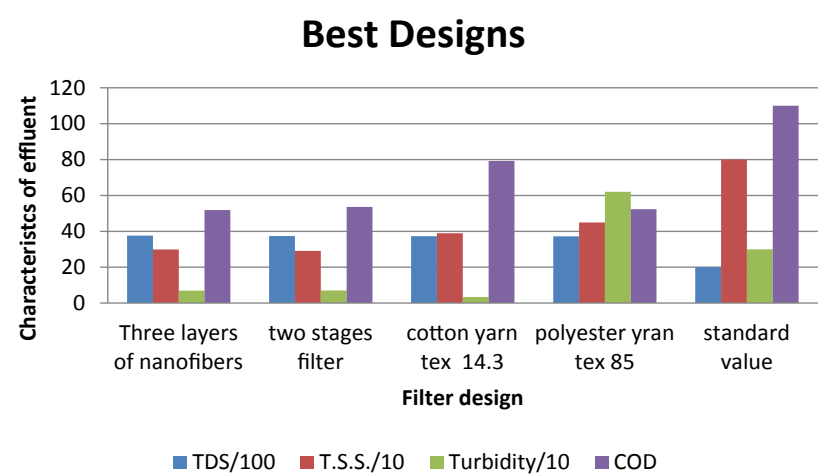

Figure 15: Comparison between best filters of Design I, Design II and Design III.

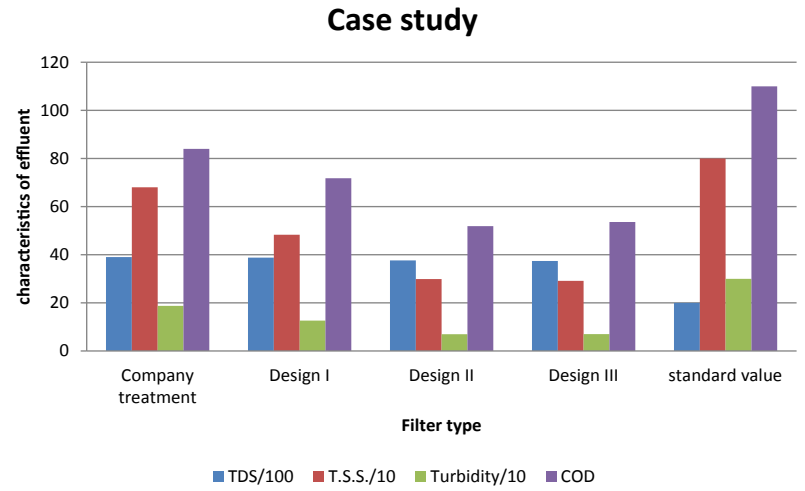

Figure 16: Results of characteristics of effluent in the case study of textile mill.

1- Pre filtration stage (using Polyester yarns of count 54 tex).

2- Filtration stage (using 3 layers nanofibers Nylon6 (24\%, 20\%, $18 \%$ Nanofiber filter).

Figure 16 results of characteristics of effluent in the case study of textile mill. The analysis of the results of the characteristics of effluent of a textile mill dying house wastewater treatment unit shows that the designed filtration unit gives better filtration efficiency concerning the levels of TSS, Turbidity, and COD.

\section{Conclusion}

Characteristics of the effluent for all filters are satisfying the required limits by the Egyptian National Environment standards for discharge of Effluent into water or land, except the value of TDS. Each design is found to have high efficiency in lowering the values of TSS, Turbidity, and COD. The use of nanofibers in the Design II and Design III made the filters more efficient in reducing the values of TSS and Turbidity. The excessive reduction of Turbidity in water, which can cause problem with water purification processes and increase the cost treatment, is considered one of the advantages of such designs. From the experimental analysis of the designed filtration units performance the following main interpretation can be drawn:

Design I: The value of TSS was reduced by $35 \%$, maximum. The filters have a significant effect on Turbidity, the reduction reaches $75 \%$. The value of COD was reduced by $40 \%$. To reduce the filter porosity: decrease the yarn count "tex", increase winding ratio, use yarns with high packing density. 
Citation: El Messiry M, Aloufy A, Elmor M (2016) Assessment of Nanofibers Filtration for Textile Waste-water Treatment. J Appl Mech Eng 5: 211. doi:10.4172/2168-9873.1000211

Page 8 of 8

Design II: The overall results of the Design II improve the characteristics of effluent better than Design I for the values of COD, TSS, and Turbidity.

Design III: Further successfully improved the values of COD, TSS, and Turbidity and the characteristic of effluent is less than that attended by the mill wastewater treatment unit.

\section{References}

1. El Messiry M (2013) Egyptian textile industry in economic crisis The $2^{\text {nd }}$ Conference for Industrial Textile Researches National Research Centre (NRC) Cairo Egypt.

2. Chavan $\mathrm{R}$, Waste minimisation few case studies

3. El-Gohary F, Ibrahim N, Nasr F, Abo-Shosha M, Ali H (2013) A new approach to accomplish waste water regulation in textile sector; an egyptian case study. Cellulose chemistry and technology 47 : 309-315.

4. Seif $\mathrm{H}$, Malak M (2001) Textile wastewater treatment. Sixth International Water Technology Conference IWTC Alexandria Egypt.

5. Babu B, Parande AK, Raghu S, Kumar T (2007) Textile technology cotton textile processing: waste generation and effluent treatment. The $\mathrm{J}$ Cotton Science 11: 141-153.

6. Judd S, Jefferson B (2003) Membranes for Industrial wastewater recovery and re-use. Elsevier Advanced Technology, The Boulevard Langford Lane Kidlington.

7. Mattioli D, Malpei F, Bortone G, Rozzi A (2002) Water minimization and reuse in the textile industry. In Water recycling and resource recovery in industry.

8. Tubtimhin S (2002) Pollution minimization and energy saving potentials in the cotton dyeing industry. Asian Institute of Technology-School of Environment Resources and Development, Thailand.

9. Parameswari M, Udayasoorian C (2013) Influence of different concentration of textile and dye effluent and sludge on soil fertility growth and yield of maize crop. J Environmental Science and Sustainability (JESS) 1: 61-65.

10. Butt $Z$. Textile waste water and its treatment.

11. Al-Kdasi A, Idris A, Saed K, Guan C (2004) Treatment of textile wastewater by advanced oxidation processes-a review. Global nest the Int J 6: 222-230.

12. EPA (1997) United States Environmental Protection Agency Publication.

13. Tüfekci N, Sivri N, Toroz I (2007) Pollutants of textile industry wastewater and assessment of its discharge limits by water quality standards Turkish Journal of Fisheries and Aquatic Sciences 7: 97-103.

14. Volmajer Valh J, Le Marechal M, Križanec A, Vajnhandl BS (2012)The applicability of an advanced oxidation process for textile finishing waste streams \& fate of persistent organic pollutants. Int J Environ Res autumn 6: 863-874.

15. Anantha Shankar R (2012) Treatment of textile effluent containing reactive red 120 dye using advanced oxidation. Dalhousie University Halifax Nova Scotia.

16. Bes-Piá A, Cuartas-Uribe B, Mendoza-Roca J, Alcaina-Miranda M (2010) J Hazardous Materials 178: 341-348.

17. Marcucci M (2001)Treatment and reuse of textile effluents based on new ultrafiltration and other membrane technologies Desalination 138: 75-82.

18. Xiaolei Qu, Alvarez PJJ, Qilin Li (2013) Applications of nanotechnology in water and wastewater treatment water research 47: 3931-3946.

19. NSF, International Protocol for the verification of wastewater treatment technologies.

20. (2015) Law number 4 of 1994 promulgating the environment law. 